\title{
Financial flexibility and the assessment of future cash flows
}

\begin{abstract}
Information on financial flexibility is important to consider when projecting the cash flows of an enterprise. The level of financial flexibility can influence inter alia the risk profile, solvency and rate of return of an enterprise. At present, a gap exists between the informational needs of users and the actual information on financial flexibility presented in the financial statements. This paper suggests several improvements to the existing disclosure of this type of information.
\end{abstract}

\section{Problem facing the financial analyst}

It is generally accepted that for an enterprise to survive, prosper and grow in the present inflationary and recessionary economic environment, good control should be exercised over cash flows.

One of the major problems encountered by the financial analyst in projecting and evaluating the cash flows of an enterprise is that existing cash flows may change due to the influences of future opportunities and threats. The analyst should therefore attempt to identify future events, assess the resulting changes in existing cash flow patterns and evaluate the effect thereof on his cash flow projections.

The following aspects of this problem warrant closer scrutiny:

- the need for historical cash flow information

- the need to predict future cash flows

- the effects of uncertain future events on cash flow patterns.

- the influence of financial flexibility on cash flow patterns.

An increasing number of enterprises are enhancing the reporting value of their financial statements by including historical cash flow statements. The information on historical cash flows assists the financial analyst in identifying the current cash flow patterns of the enterprise. This enables him to project future cash flows and to determine their influence on the future liquidity, profitability, solvency and risk of the enterprise.

Projected cash flows may indicate whether the enterprise is generating sufficient cash to:

- maintain its current operating capacity

- pay its liabilities, interest and divident on due dates

- invest in the future expansion and growth

- survive in the current inflationary environment.

Thus the information derived from the future cash flows contribute to the analyst's knowledge of the enterprise and ultimately to the final decision of whether to invest or not.

An enterprise operates in a dynamic environment where even daily events, be they threats or opportunities, may alter the envisaged strategies of the enterprise. It is further apparent that such events may alter the cash flow patterns of the enterprise. The financial analyst needs to take cognisance of the potential effects that unexpected future events may have in determing his cash flow projections. It is difficult to predict future threats and opportunities but the analyst should use his knowledge of the enterprise, the industry and his economic forecasts to identify some of these future events.
The environment in which enterprises operate forces them to review and alter their cash flow patterns regularly. As unexpected adversities and opportunities assail the enterprise, management will weigh the available strategies and will select the most feasible alternative to meet the changed circumstances. The set of feasible alternatives available to management to change, inter alia, the current cash flow patterns may be described as the financial flexibility of the enterprise. The analyst needs to evaluate and assess the influence of financial flexibility as this may have a direct impact on the future success of the enterprise.

The projection of future cash flows is complicated by the uncertainty of the future events and the uncertainty of the enterprise's reactions to these events. Information on financial flexibility can assist the analyst by identifying feasible alternatives and thus reducing the uncertainty of the enterprise's reactions to future events. This is confirmed in The Discussion Memorandum (1980) issued by the Financial Accounting Standards Board (FASB), which states that information on financial flexibility is relevant for the assessment of only part of the uncertainty in the cash flow prospects of an enterprise. It is further apparent that the greater the number of feasible alternatives available to an enterprise, the higher the financial flexibility of the enterprise. It follows that a high level of financial flexibility reduces the number of threats and increases the available opportunities to the enterprise.

The influence and importance of financial flexibility on the future cash flows of an enterprise is addressed in this paper. In particular, the need of the analyst for information on financial flexibility to assist in predicting cash flows is contrasted to the minimum information on financial flexibility presently required and disclosed in the financial statements of enterprises.

A review of available literature has indicated that little emphasis has as yet been placed on the importance of information on financial flexibility in South Africa. This may largely be due to the fact that the needs of the users of financial statements for information on financial flexibility have not yet been researched. In the United States, a Discussion Memorandum (1980) on reporting funds flows, liquidity and financial flexibility, addressed in some depth, the importance of, and the type of information on, financial flexibility that could be included in the corporate report of enterprises. No evidence could be found of any such specialised research study completed in South Africa. Thus, the specific needs of users in South Africa for information on financial flexibility have not yet been identified.

Financial analysts' need for information on financial flexibility

As information on financial flexibility is important to the analyst in predicting cash flows, the relevant and useful information which should be available to the user, is now addressed. To identify the information needs of the analyst, it is necessary however to define financial flexibility.

Financial flexibility is defined in paragraph 16 of Discussion Paper 8 (1985):

"Financial flexibility may be regarded as the ability to con-

- Department of Accounting, University of the Witwatersrand 


\section{SEEKING OUT}

AN ENVIRONMENT THAT PROMISES

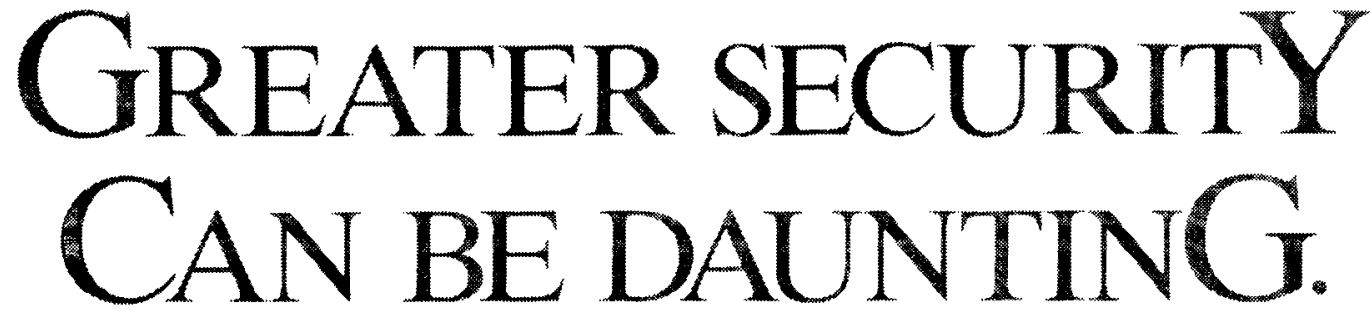

BUT NEVER COMPROMISE.

BECAUSE WHEN YOU

FIND IT, YOU'LL KNOW YOU HAVE ALL THE

SHELTER AND GROWTH YOU WILL EVER NEED.

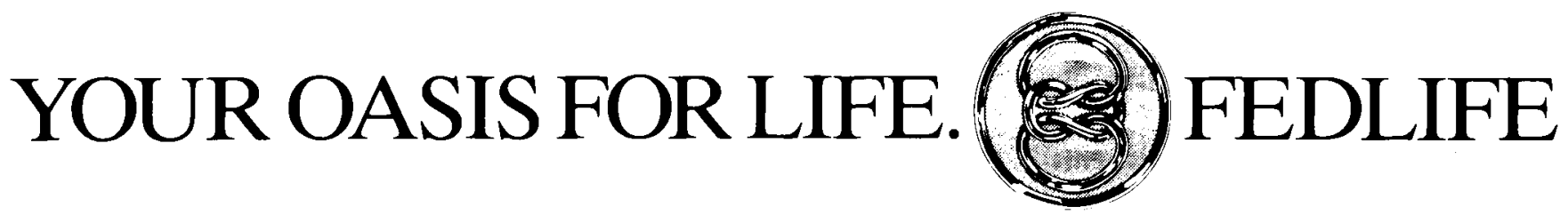

MEMBER OF FEDSURE GROUP • S.A.'S LARGEST INDEPENDENT LIFE ASSURER • ASSETS EXCEEDING R2 BILLION 1987 NET PREMIUM INCOME R293 MILLION • AVERAGE ANNUAL GROWTH OF NEW PREMIUMS OVER LAST 5 YEARS - 46\% 
trol and adjust cash receipts and payments to respond to adversities and opportunities."

This definition is similar to that used in the Statement of Financial Accounting Concepts No. 5 (1984) except for a more direct identification of what is seen as "the ability to control and adjust receipts and payments." The definition states:

"Financial Flexibility is the ability of an entity to take effective actions to alter amounts and timings of cash flows so that it can respond to unexpected needs and opportunities."

It may be concluded from the above definitions that the information on financial flexibility should identify the feasible alternatives available to management to change the current cash flow patterns of the enterprise in response to threats and opportunities.

The Discussion Memorandum (1980) issued by the Financial Accounting Standards Board (FASB) identifies the importance of financial flexibility as being:

". . . a measure of the adaptability of a business. The need for adaptability may be offensive or defensive. A business may need financial flexibility to take advantage of an unexpected new investment opportunity or to survive a crisis resulting from a change in operating conditions. Financial flexibility comes from quick access to cash. A financially flexible business may have a large inflow of cash from operations, large borrowing capabilities, or assets that can be realized quickly in significant amounts."

In the light of the definitions on financial flexibility, it is now possible to address the needs of analysts, as a major user group of financial statements, for information on financial flexibility. It has been established in reviewing the problems that analysts encounter that they will benefit from information on financial flexibility.

\section{General information requirements}

Some of the general information requirements to evaluate financial flexibility can be identified. In an attempt to establish guidelines for evaluating potentially useful information, four major groups of information, not necessarily mutually exclusive, are identified:

- the potential for utilising finance

- the potential for altering investment strategies

- the potential for altering operations

- other qualitative and quantitative information.

\section{The potential for utilising finance}

Information on the potential for utilising finance may be subdivided into the potential to raise and repay equity capital, the potential to raise and repay outside finance and the potential for changing the existing financing structures.

Information on the potential to raise and repay equity capital is useful to the analyst in establishing the probability of the enterprise issuing or redeeming share capital in response to future events. Relevant information on this type of financial flexibility may include the details of unissued shares, the latest share issue prices, the premiums payable on the redemption of preference shares, the dividend policy, details of share options, present market prices and details of any conversion rights. The analyst requires adequate information to be able to assess the amount and timing of cash flows from the issue or repayment of shares as well as the payment of dividends.

For information about the potential for raising or repaying outside finance, the conditions and durations of all existing loans should be available. If the Articles of Association of the enterprise impose limitations on the borrowing capacity, then the unutilised borrowing capacity is important information in evaluating the financial flexibility of the enterprise for raising out- side finance to meet unexpected events. Everingham and Hopkins (1982) state further that information on any restrictions placed on the future borrowings of the enterprise by existing loan agreements should be disclosed as this will also affect the analyst's evaluation of the financial flexibility. Other relevant information may include the market value or net realisable value of all unbonded, non-operating and separable assets, details of available unsecured loans and other unutilised lines of credit, unutilised bank overdraft facilities and credit ratings with financial rating agencies.

The financing structure may be altered by changing the relationship between equity capital and outside finance and the relationship between long-term and short-term finance. Relevant information may thus include the gearing targets and rates of return targets set by management, as well as the available options for utilising specialised finance such as government subsidies, decentralization allowances, strategic loans and export allowances. In this regard the Discussion Memorandum (1980) of the FASB confirms that the disclosure of management discussions and the analysis of information about the policies and the plans for future investing and finance activities may be useful for assessments of the financing capacity and thus the financial flexibility of an enterprise.

\section{The potential for altering investment strategies}

Future cash flows can be altered by changes in the enterprise's investment strategies as cash flows may be generated by, for example, disposing of non-operating and separable assets without necessarily disrupting operations. Relevant information may include information on the leasing policies of the enterprise. Decisions to enter into sale and leaseback arrangements or financial and operating leases rather than acquiring ownership of new assets, can materially alter the future cash flow patterns of the enterprise. The discontinuance of material segments of the enterprise will influence not only the existing investment strategies, but will also alter the existing operations. At present, segmental reporting identifies the material segments of the enterprise and may serve as a basis for identifying the potential effects on future cash flow patterns. The altering of existing short-term investment policies such as the granting of credit terms, the changing of stock levels and the investment or disinvestment in speculative investments may also influence cash flows.

\section{The potential for altering operations}

The existing amount of cash generated from operations can be altered materially by changing the cash inflows or cash outflows from operations. Relevant information to the analyst may include plans for future changes in production, increased markups on costs, reductions or increases in fixed and variable costs, reorganisation of production lines, introduction of new products or the discontinuance of existing products or business segments, potential new markets and changes in competitors. The operations will also be influenced by the turnover rates of the working capital and the length of the operating cycle. In this regard the FASB Discussion Memorandum (1980) notes that the faster an enterprise's assets can be converted to cash, the greater its financial flexibility.

\section{Other quantitative and qualitative information}

The potential for changes in cash flow patterns, can be altered by decisions regarding:

- future expansion and diversification plans

- capital commitments

- changes in group structures

- listing or delisting of an enterprise on a stock exchange

- changing the legal structure of the entity (for example from a company to a close corporation) and

- contingent liabilities. 
South Africa's major gold mines are to be found along the northern rim of a huge depression formed nearly three billion years ago and known as the Witwatersrand basin. This golden arc is believed by geologists to be the shoreline of an ancient inland sea.

It was through Gold Fields' exploration initiatives west of Johannesburg in the early 1930's that this shoreline began to reveal itself. In 1931 Gold Fields committed the then princely sum of $£ 500$ to the preliminary investigation of that section of the arc which is today known as the West Wits Line. And the world's greatest gold find.

Today, the Gold Fields group is still in search of new treasure - spending some R34 million on exploration in 1988 alone.

Because for those with the entrepreneurial spirit, the shoreline never ends.

\section{What kind of investor would sink money into a sea without water?}

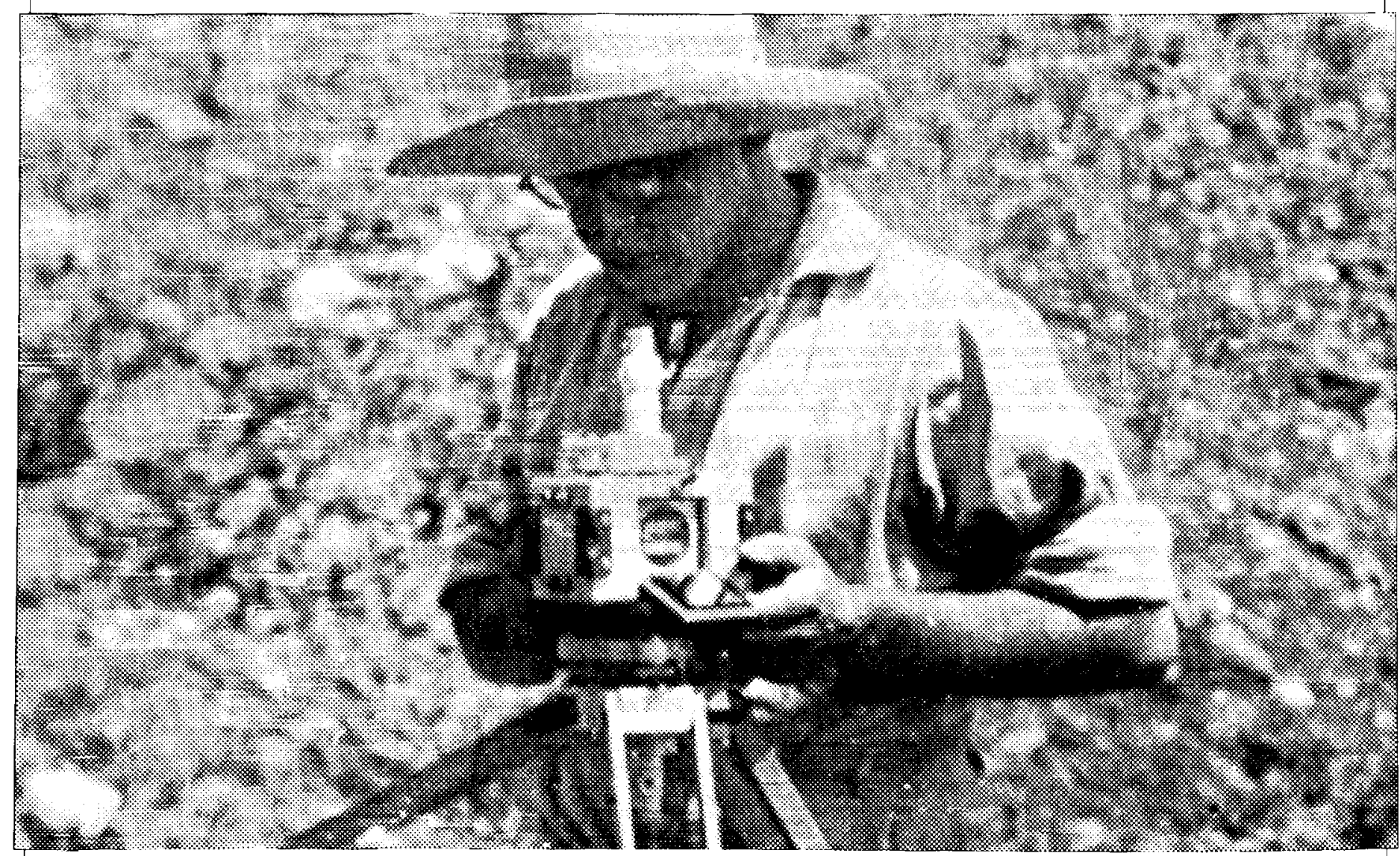

Gold Fields' geophysicist Dr. Rudolf Krahmann, surveying the West Wits Line - 1931

\section{GOLD FIELDS OF SOUTH AFRICA LIMITED}

Enriching man through minerals 


\section{The relationship between financial flexibility and risk}

There is an inverse relationship between financial flexibility and risk; the lower the financial flexibility of a company becomes, the higher the risk becomes.

"An enterprise that has fully utilised its borrowing capacity in the capital intensive projects may achieve extremely high rates of return but at the expense of sacrificing its financial flexibility and increasing its risk profile." (Everingham and Hopkins (1982))

Any decisions affecting financial flexibility should be made within the parameters of risk and rate of return. A low financial flexibility may ultimately influence the solvency of an enterprise facing adverse circumstances and may be critical to the survival of that enterprise (Discussion Memorandum (1980)). Information on recent changes in the financial flexibility of an enterprise is thus important in evaluating the risk profile.

\section{Developments in cash flow reporting}

The developments in cash flow reporting in the United States and South Africa are discussed briefly to explain the reasons for the change to cash based reporting. This change has emerged as a result of the recognition of the importance of managing cash and, inter alia, evaluating financial flexibility.

The Statement of Changes in Financial Position forms part of the financial statements of enterprises and until recently was usually reconciled to the net movement in working capital. The importance of cash management to the success of an enterprise has led to an increasing number of enterprises presenting their Statements of Changes in Financial Position on the cash approach.

In the Statement of Financial Accounting Concepts No. 1 (1978) it is concluded that financial reporting should provide information that is helpful in assessing the amount, timing and uncertainty of prospective cash flows of an enterprise. Of interest is that the concepts statement requires not merely historical information but also information useful in projecting cash flows. It is apparent, therefore, that enterprises should include relevant information to assist analysts in forecasting cash flows and reducing future uncertainties.

The Statement of Financial Accounting Concepts No. 5 (1984) elaborates further on the information required on cash flows:

"Statements of Financial Position include information that is often used in assessing an entitiy's liquidity or financial flexibility, but a statement of financial position provides only an incomplete picture of either liquidity or financial flexibility unless it is used in conjunction with at least a cash flow statement."

The importance of information on financial flexibility was discussed further in the FASB Discussion Memorandum on Reporting Funds Flows, Liquidity and Financial Flexibility (1980). This Discussion Memorandum identifies specifically the types of information that can assist users in assessing financial flexibility. The key factors in assessing financial flexibility which may require disclosure in the financial statements are identified as:

- the nearness to cash of investments

- the ability to obtain additional financing

- the amount of operating assets

- the ability to increase short-term funds flows by modifying operating and investing activities, including the ability to discontinue operations or sell operating assets.

Although the term financial flexibility is subsequently included in the FASB Exposure Draft on Cash Flow Information (1986) and recently in the Statement of Cash Flows (1987), those proposals omit details as to the type of information on financial flexibility that should be contained in the financial statements.
It is merely noted in the Statement of Cash Flows (1987) that: "Important uses of information about entity's financial position include helping users to assess factors such as the entity's liquidity, financial flexibility, profitability and risk."

The Accounting Practices Committees (APC) of the South African Institute of Chartered Accountants issued a Discussion Paper on Cash Flow Statements in 1985. The Discussion Paper was subsequently replaced by Exposure Draft No. 63 (1986). Both these papers concluded that the provision of cash flow information ensures that the users of financial statements are better informed as to liquidity and financial flexibility. They fail, however, to address the type of information on financial flexibility that should be included in the financial statements. In South Africa, therefore, very little emphasis has been placed on financial flexibility information when drafting the financial statements of an enterprise.

While information required by Schedule 4 of the Companies Act may be relevant to cash flow projections, this information is not recognised in the context of financial flexibility. Other information on financial flexibility may be contained elsewhere in the corporate report. It is, thus, apparent that the analyst wishing to assess the effects of financial flexibility on an enterprise's future cash flows must scrutinize the financial statements in detail, in order to seek out all reported information relevant to his predictions.

It is clear that the preparers of the financial statements, have access to all information, as well as a specialised knowledge of the enterprise's business and future prospects. It is, therefore, encumbent on them to communicate this information to the user in the most meaningful format. The relevant information may vary from enterprise to enterprise and currently its disclosure depends largely on the discretion of the preparer. A guideline on disclosure requirements may to some extent standardize and improve the disclosure of information on financial flexibility. This would ensure that relevant information is neither omitted nor overlooked. If the objective of financial statements is indeed to provide information helpful in assessing the amount, timing and uncertainty of prospective cash flows, such statements will be sadly lacking if they do not contain adequate information on financial flexibility.

The preparer of financial statements wishing to include information on financial flexibility may however be faced with several problems. Information on financial flexibility should, inter alia, assist the user in establishing the influence thereof on future cash flows and thus information on future trends, events and decisions are required. This presents the preparer with two main problems concerned, respectively, with:

- the objectivity and verifiability of information concerning the future, and

- the sensitivity and confidentiality of information, the disclosure of which could affect the enterprise detrimentally.

Another factor that the preparer should bear in mind is the cost of including the information on financial flexibility versus the benefit to be derived from the information. Only if the benefits derived from the information by the analysts and other users exceed the costs of including the information in financial statements, is it feasible to include the relevant information on financial flexibility. At present it may be difficult to assess the benefits that users will derive from the information as the specific needs of users for information on financial flexibility is not yet clear.

The preparer may not find it feasible to group all information on financial flexibility under a separate heading as the information tends to be of an interrelated nature thus also pertaining to other sections of the financial statements. It is further submitted that information on financial flexibility is not only obtained from or used with a cash flow statement. In this regard the Statement of Financial Accounting Concepts No. 5 (1984) 

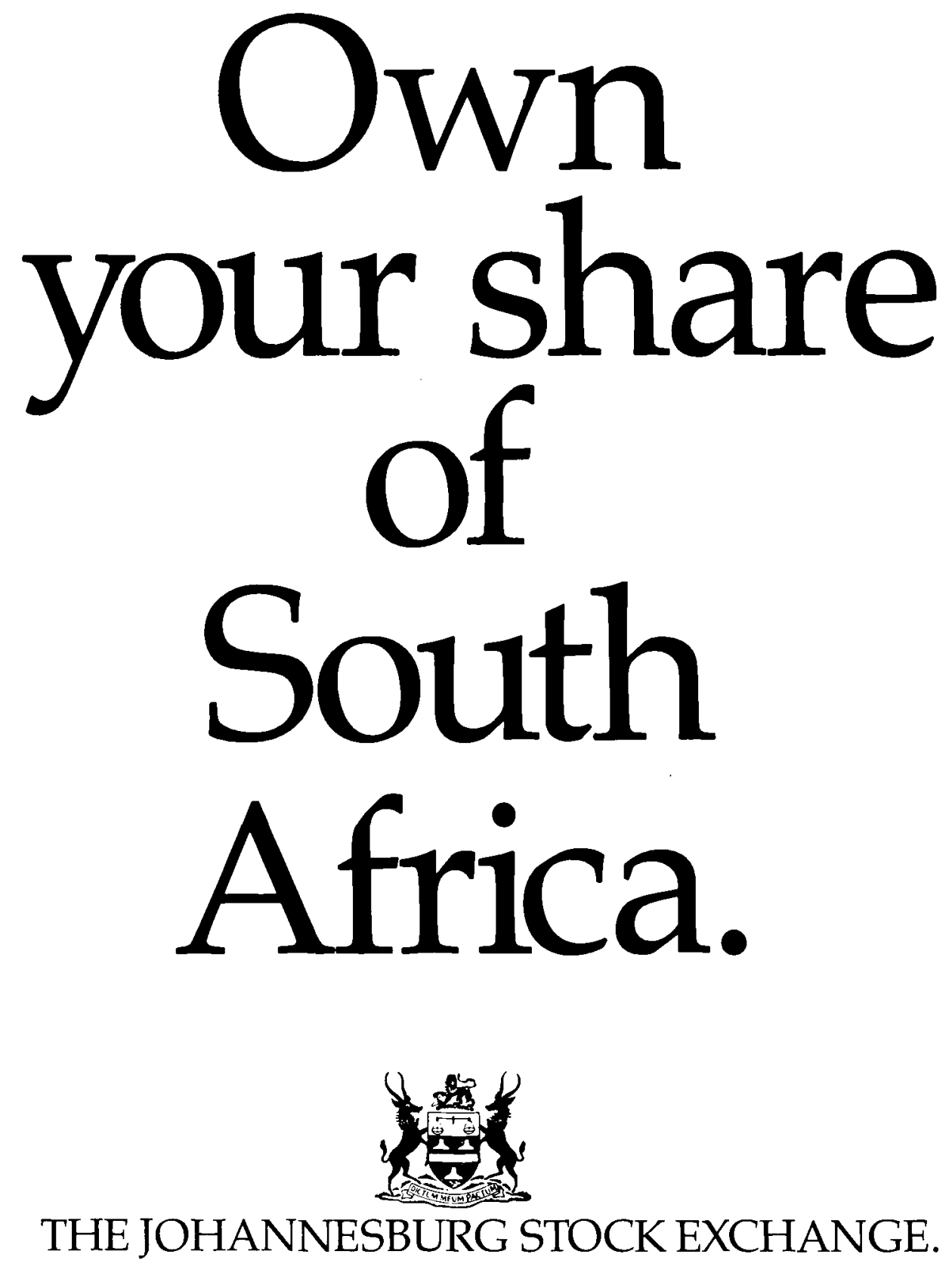

USCHARRER, EINARDS, FRASER 816 
states that information on financial flexibility should be used in conjunction with at least a cash flow statement. This is confirmed in the Statement of Financial Accounting Standards No. 95 (1987) where it is stressed that the statement of cash flows should not be used in isolation, but should be used in conjunction with the other components of the financial statements to enhance the value to the analyst.

\section{Suggestions for improvements}

At present, there appears to be a gap between the information requirements of the users (specifically the analyst) and the information on financial flexibility contained in the financial statements. The situation is aggravated by the fact that no guideline exists in South Africa as to the minimum information on financial flexibility to be included in the financial statements and further that no empirical study has as yet identified the specific needs of users for information on financial flexibility.

It is therefore suggested that:

- research is necessary to identify the specific needs of analysts and other user groups for information on financial flexibility

- preparers of financial statements become aware of the users' need for information on financial flexibility and consider presenting the relevant information in the notes to the financial statements or in the information outside the financial statements, such as in the form of summary tables highlighting borrowing capacity, the cash flow cycle, recovery rates and target ratios

- the pending South African Accounting Statement on cash flow information should address the issue of what constitutes minimum disclosure requirements for information on financial flexibility and

- consideration be given to expanding segmental reporting to include information on financial flexibility.

\section{Acknowledgement:}

The author wishes to express her appreciation for the assistance received from professor $M D F$ Steele and $M r J W M$ Mende, both of the Department of Accounting.

\section{References:}

Accounting Practices Committee of the South African Institute of Chartered Accountants, Cash Flow Information, Discussion Paper No. 8 (DP8), 1985.

Accounting Practices Committee of the South African Institute of Chartered Accountants, Cash Flow Information, Exposure Draft No. 63 (ED63), 1986.

Accounting Standard Board of the Institute of Chartered Accountants in Australia Statement of Sources and Application of Funds, Statement of Accounting Standards, 1987.

Ernst and Whinney, Reporting Funds Flows, Liquidity and Financial Flexibility, Financial Reporting Developments Report on FASB Discussion Memorandum 1981, p 17

Everingham, G K and Hopkins, B D. (1982). Generally Accepted Accounting Practice, Second Edition, Tenth Update, Juta, p 381.

Everingham, G K and Hopkins, B D. (1985). Seminar on New Developements in Financial Reporting.

Financial Accounting Standards Board, Objectives of Financial Reporting, Statement of Financial Accounting Concepts No. 1 (SFAC No. 1), 1978, par 25.

Financial Accounting Standards Board, Reporting Funds Flows, Liquidity and Financial Flexibility, Discussion Memorandum 1980, pp $107-123$.

Financial Accounting Standards Board, Recognition and Measurement in the Financial Statements of Business Enterprises, Statement of Financial Accounting Concepts No. 5 (SFAC No. 5), 1984, par 24 and par 52.

Financial Accounting Standards Board, Statement of Cash Flows, Proposed Statement of Financial Accounting Standards No. 023 (SFAS No. 023), 1986.

Financial Accounting Standards Board, Statement of Cash Flows, Statement of Financial Accounting Standards No. 95 (SFAS No. 95), 1987.

International Accounting Standards Board, Statement of Changes in Financial Position, International Accounting Standard No. 7 (IAS7), 1979. 